\title{
Local administration of insulin-like growth factor-I (IGF-I) stimulates tendon collagen synthesis in humans
}

\author{
M. Hansen ${ }^{1,2}$, A. Boesen ${ }^{1}$, L. Holm ${ }^{1}$, A. Flyvbjerg ${ }^{2}$, H. Langberg' ${ }^{1}$ M. Kjaer ${ }^{1}$ \\ ${ }^{1}$ Institute of Sports Medicine, Department of Orthopedic Surgery M81, Bispebjerg Hospital and Center for Healthy Aging, Faculty of \\ Health Sciences, University of Copenhagen, Copenhagen, Denmark, ${ }^{2}$ Department of Endocrinology and Internal Medicine, Aarhus \\ University Hospital and The Medical Research Laboratories, Institute of Clinical Medicine, Faculty of Health Sciences, Aarhus \\ University, Aarhus, Denmark \\ Corresponding author: Mette Hansen, Institute of Sports Medicine, Copenhagen, Build. 8, Bispebjerg Hospital, Bispebjerg Bakke 23, \\ DK-2400 Copenhagen NV, Denmark. Tel: +45 353160 89, Fax: +45 353127 33, E-mail: kontakt@mettehansen.nu
}

Accepted for publication 28 November 2011

Collagen is the predominant structural protein in tendons and ligaments, and can be controlled by hormonal changes. In animals, injections of insulin-like growth factor I (IGF-I) has been shown to increase collagen synthesis in tendons and ligaments and to improve structural tissue healing, but the effect of local IGF-I administration on tendon collagen synthesis in human has not been studied. The purpose of this study was to study whether local injections of IGF-I would have a stimulating effect on tendon collagen synthesis. Twelve healthy nonsmoking men [age $62 \pm 1$ years (mean \pm SEM), BMI $27 \pm 1$ ] participated. Two injections of either human recombinant IGF-I (0.1 mL Increlex@) or saline (control) into each patellar tendon were performed 24-h apart, respectively. Tendon collagen fractional synthesis rate (FSR) was measured by stable isotope technique in the hours after the second injection. Simultaneously, interstitial peritendinous (IGF-I) and [procollagen type I N-terminal propeptide (PINP)], as a marker for type I collagen synthesis, were determined by microdialysis technique. Tendon collagen FSR and PINP were significantly higher in the IGF-I leg compared with the control leg $(P<0.05)$. In conclusion, local IGF-I administration can directly enhance tendon collagen synthesis both within and around the human tendon tissue.
Tendon and ligaments play an important role for the force-transmitting function of the muscular-skeletal system, and collagen represents the most common and structural important protein in these structures (Finni et al., 2000). The regulatory role of different hormonal growth factors and cytokines in humans in relation to stimulation of tendon and ligament synthesis is not fully clarified (Kjaer, 2004), but a rise in expression and tissue content of insulin-like growth factor I (IGF-I) is found to be associated with a rise in tendon collagen synthesis after mechanical loading (Langberg et al., 1999; Miller et al., 2005; Heinemeier et al., 2007; Olesen et al., 2006b). Furthermore, a stimulating effect of IGF-I on collagen synthesis in tendon/ligament tissue is supported by in vitro studies, which have shown that IGF-I directly stimulates fibroblast proliferation and synthesis of extracellular matrix proteins (e.g., collagen) in tendon and ligament explants (Abrahamsson et al., 1991a, b; Abrahamsson \& Lohmander, 1996; DesRosiers et al., 1996; Murphy \& Nixon, 1997). Thereby, IGF-I injections promote tendon and ligament healing in animals after collagenase-induced tissue atrophy (Dahlgren et al., 2002) or ligament disruption (Kurtz et al., 1999; Provenzano et al., 2007). In humans, muscle collagen expression is positively correlated to muscle IGF-IEa expression in patients with acromegaly and growth hormone (GH) deficiency (GHD) (Doessing et al., 2010b). Finally, after systemic GH administration for 14 days, human data have demonstrated an increase in circulating IGF-I and expression of IGF-I in tendon tissue and an accompanying rise in tendon collagen mRNA expression and tendon collagen synthesis in young healthy individuals (Doessing et al., 2010a). The later finding supports a potential regulatory role of the GH/IGF-I axis upon tendon collagen synthesis in humans, but neither provides any direct proof for a causative effect nor is able to identify whether IGF-I or rather $\mathrm{GH}$ is the regulating factor for collagen synthesis in human tendon. Thus, the present study was designed to test the hypothesis that local IGF-I administration induces an elevation in collagen synthesis in human tendon tissue. 


\section{Hansen et al.}

\section{Subjects and methods}

\section{Subjects}

Twelve healthy men [62 \pm 1 years (range 55-70 years); weight: $88 \pm 3 \mathrm{~kg}$; height: $181 \pm 1 \mathrm{~cm}$; body mass index (BMI): $27 \pm 1$; body fat $\%: 28 \pm 1 \%$; and maximal oxygen uptake $\left(\mathrm{VO}_{2 \max }\right.$ est $)$ : $35 \pm 2 \mathrm{~mL} \mathrm{O} / \mathrm{min} / \mathrm{kg}$ ] were enrolled in the study. The local Ethics Committee for Medical Research in Copenhagen (H-B2009-032) approved the protocol. Prior to inclusion, informed written and oral consent was obtained from each subject according to the Declaration of Helsinki. Each subject underwent a medical evaluation, including routine blood tests, and underwent body composition evaluation and had their maximal exercise capacity tested. Exclusion criteria for participation in the study were diabetes, obesity (BMI above 30), smoking, skeletal muscle diseases, hypermobility, previous or present knee injuries, medicine with a potential effect on connective tissue, and screening blood samples values outside normal range.

\section{Health examination and screening}

One to 3 weeks prior to the experimental days, the subjects underwent health examination and screening procedures, which included questionnaires about disease and training history, blood samples, and height, weight and skinfold measurements. Blood samples were analyzed for plasma concentrations of creatinine, creatinine kinase, calcium, c-reactive protein, basic phosphatase, asparate aminotransferase, alanine transaminase, erythrocyte volume fraction, sodium, potassium, blood concentrations of hemoglobin $(\mathrm{Hb})$, thrombocytes, leucocytes, and $\mathrm{HbA} 1 \mathrm{c}$ and serum concentrations of thyroid stimulating hormone. Fat mass $(\%)$ was determined by the skinfold technique. Estimated maximal oxygen uptake $\left(\mathrm{VO}_{2 \max }\right.$, est $)$ was estimated by a 10 -min two-step submaximal bike test. The workload was increased once after $6 \mathrm{~min}$ and the heart rate registered when it was stable.

\section{Study design}

The study was designed as a placebo-controlled, double-blinded study comparing effects of a two local injections of either IGF-I or saline (control) on tendon collagen synthesis. In the morning at day one of the experiment, one bolus of IGF-I was injected into the patellar tendon of one leg and a similar volume of saline was injected into the contralateral patellar tendon. The following morning, the procedures were repeated. During the subsequent hours, tendon collagen synthesis was measured directly by stable isotope incorporation and indirectly by microdialysis technique (Fig. 1).

\section{Experimental days}

On each of the two experimental days, each subject attended the laboratory at 8:00 h after an overnight fast. No strenuous physical exercise was allowed 2 days preceding the experimental days to ensure that mechanical loading caused no stimulation of tendon collagen synthesis above the stimulus from normal everyday activities. Each subject was instructed to continue normal dietary habits while enrolled in the study period.

\section{IGF-I and saline injections}

Because this is the first time IGF-I is injected into human patellar tendons with the purpose to raise tendon collagen synthesis, the delay from the injection of IGF-I until a stimulation of tendon collagen synthesis potentially could be detected was not known. After acute exercise, we have observed an increase in tendon
Day 2 of the experiment

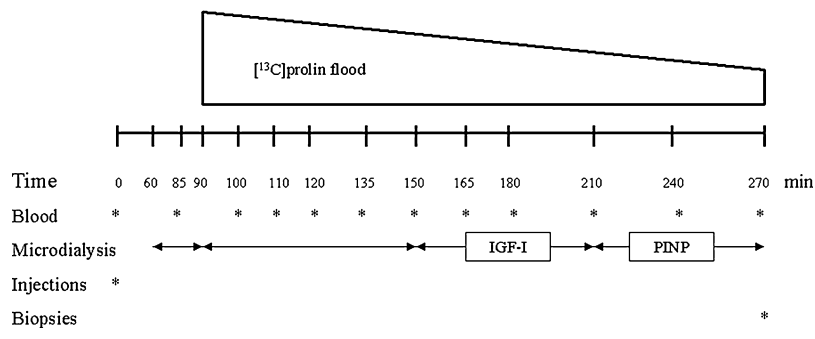

Fig. 1. Overview of the study protocol during day 2 of the experiment. Schedule of the application of insulin-like growth factor I (IGF-I)/saline injections, the flooding dose of labeled proline, blood sampling, sampling of dialysate by microdialysis technique for IGF-I, and PINP (amino terminal propeptide of type I collagen) analyses and sampling of tendon biopsies.

fractional synthesis rate (FSR) a few hours after exercise, peaking $24 \mathrm{~h}$ post-exercise (Langberg et al., 1999; Miller et al., 2005). Thus, there may be a time lag from the time of IGF-I injection until a stimulating effect on tendon collagen FSR can be measured. If it mimics the time lag from the end of acute exercise to the enhancement of tendon collagen FSR, one injection of IGF-I $24 \mathrm{~h}$ before measuring tendon collagen FSR would be the most appropriate. Nevertheless, the response time might also be shorter. Thus, as the main purpose of the present study was to explore whether tendon collagen FSR can be stimulated by administration of IGF-I locally in the tendon tissue, two injections of IGF-I both $3 \mathrm{~h}$ and $24 \mathrm{~h}$ before the measurements of tendon collagen FSR was performed to reduce the risk of overseeing a positive effect of the IGF-I administration.

The two local injections of recombinant human (rh) IGF-I (each $1 \mathrm{mg}$ corresponding to $0.1 \mathrm{~mL}$ INCRELEX $\odot$, Tercica Europe Ltd., Dublin, Ireland) into the patellar tendon were performed randomly between subjects into either the dominant or nondominant leg. Saline (control) was injected into the contralateral patellar tendon. The injections were performed under ultrasound guidance $1 \mathrm{~cm}$ distal from the distal patella tip. At day one of the experiment, the subjects rested in bed for $1 \mathrm{~h}$ after the IGF-I and saline injections to minimize the disappearance of the infused IGF-I from the tendon area. The following day, the IGF-I and saline injections were repeated in the same leg, respectively, as on the previous day. After the second bilateral injection the subjects stayed in bed and fasted until the end of the experiment. The subjects were allowed to drink water freely throughout the period.

We wanted to inject as high a dose of IGF-I to ensure the stimulation of tendon collagen synthesis; on the other hand, we did not want to enhance circulating IGF-I and thereby transfer the effect of the IGF-I injection to the contralateral control leg. The recommended dose of IGF-I administered to children with primary IGF-I deficiency is two daily injections of 0.04$0.12 \mathrm{mg} / \mathrm{kg}$ each. Assuming a body weight, as the subjects in the present study (average body weight: $88 \mathrm{~kg}$ ), would correspond to a treatment dose between 7 and $21 \mathrm{mg}$ per day. Assuming the knee region corresponds to $2 \mathrm{~kg}$ would result in a dose between 0.16 and $0.48 \mathrm{mg}$ per day. Based on these calculations and our concerns regarding enhancement of circulating IGF-I, we chose a dose of $1 \mathrm{mg}$ IGF-I per injection per day.

\section{Tendon collagen synthesis measured by stable isotope technique}

Measurement of tendon collagen FSR were performed according to previously applied approaches (Babraj et al., 2005; Miller et al., 


\section{Effect of IGF-I on tendon collagen synthesis}

2005). Briefly, a flooding dose of proline $(3.75 \mathrm{~g}$ total; $0.75 \mathrm{~g}$ labeled L-1 $1{ }^{13} \mathrm{C}$-proline ( $>99$ Atoms $\%{ }^{13} \mathrm{C}$-proline, Cambridge Isotope Laboratories, Andover, MA, USA), $3.0 \mathrm{~g}$ unlabeled ${ }^{12} \mathrm{C}-$ proline (AppliChem, Darmstadt, Germany) was dissolved in $0.9 \%$ $\mathrm{NaCl}$ using a sterile technique, and intravenously infused over $3 \mathrm{~min} 1.5 \mathrm{~h}$ after the last tendon injections. After flooding, blood samples were drawn at 10-30-min intervals to determine the area under the ${ }^{13} \mathrm{C}$-proline enrichment curve in plasma measured as tracer-to-tracee ratio. Three hours later, the isotope flood tendon biopsies were taken from the patella tendon $(\sim 10 \mathrm{mg})$ of each leg after a sterile wash of the skin and anesthetizing the skin at incision sites with lidocaine, $1 \%$. Subsequently, a 3- to 5-mm-long skin incision was created using a scalpel. The biopsies were obtained by using a Bard MAGNUM Biopsy Instrument (C.R. Bard, Inc, Covington, GA, USA) with a 14-gauge disposable core biopsy needle under ultrasound guidance. The biopsy needle was inserted through this incision onto the tendon surface at an approximately $30^{\circ}$ angle and fired. Biopsies were cleaned free of external adipose tissue and blood, and inspected under microscope, frozen in liquid nitrogen, and stored at $-80^{\circ} \mathrm{C}$ for subsequent analysis.

Plasma proline enrichment. Plasma proline was prepared as previously described and analyzed as its $t$-butyldimethylsilyl derivative by gas chromatography (Trace GC 2000 series) and mass spectrometry (Automass Multi, Thermo Quest Finnigan, Paris, France) (Schwenk et al., 1984; Babraj et al., 2002), and separated by a capillary column (CP-SIL 8, CB low Bleed, $30 \mathrm{~m} \times 0.32 \mathrm{~mm}$, coating $0.25 \mu \mathrm{m}$ column, Chrompack, Varian, Palo Alto, CA, USA).

Tendon preparation. Details regarding this procedure have been given elsewhere (Babraj et al., 2005; Miller et al., 2005). Briefly, tendon $(5-10 \mathrm{mg}$ ) biopsies were homogenized in buffer $(0.15 \mathrm{M} \mathrm{NaCl}, 0.1 \%$ Triton X-100, and $0.02 \mathrm{M}$ Tris- $\mathrm{HCl}, 5 \mathrm{mM}$ EDTA, pH 7.4), centrifuged with $1600 \mathrm{~g}$ and the pellet subsequently washed with $0.7 \mathrm{M} \mathrm{KCl}$, centrifuged with $1600 \mathrm{~g}$ and the pellet hydrolyzed in $6 \mathrm{M} \mathrm{HCl}$ at $110{ }^{\circ} \mathrm{C}$ overnight. Amino acids were then extracted through disposable columns using acidic cation exchange resin (Dowex AG-50W, Bio-Rad, Sundbyberg, Sweden). The amino acids were derivatized as their N-acetyl-npropyl esters (Meier-Augenstein, 1999), and the ${ }^{13} \mathrm{C}$ abundance under the proline peak was determined by gas chromatograph combustion isotope ratio mass spectrometry (Delta Plus XL, Thermo Finnigan, Bremen, Germany) using a column CP-SIl 19 CB $60 \mathrm{~m} \times 0.32 \mathrm{~mm}$, coating $0.25 \mu \mathrm{m}$ (ChromPack, Varian, Palo Alto, CA, USA).

Calculations. Plasma ${ }^{13} \mathrm{C}$-proline enrichment was assumed to represent the enrichment of the true precursor pool, prolyl-tRNA (Babraj et al., 2002). Thus, the tendon collagen synthesis was calculated according to the precursor-product principle as: Fractional protein synthesis $(\mathrm{FSR} \% / \mathrm{h})=\Delta \mathrm{E}_{\mathrm{t}} \times 100 \% / \mathrm{AUC}_{\mathrm{p}}$, where $\Delta \mathrm{E}_{\mathrm{t}}$ is the difference in ${ }^{13} \mathrm{C}$-proline abundance between the tendon collagen protein sample obtained $3 \mathrm{~h}$ after the ${ }^{13} \mathrm{C}$-proline flood, and the plasma proline labeling in the venous blood sample obtained prior the tracer flood, and $\mathrm{AUC}_{\mathrm{p}}$ is the area under the curve of venous proline labeling with the exact time in hours from the flood until the individual biopsies are obtained.

\section{Tendon collagen synthesis measured by microdialysis}

Fluid collected from the interstitial fluid surrounding the patellar tendon by using a microdialysis technique was analyzed for a marker of type I collagen synthesis, the amino terminal propeptide of type I collagen (PINP) as previously described in detail (Langberg et al., 1999). After initial preparation of incision sites with local anesthetic (lidocaine 1\%) ethylene oxide sterilized catheters with high molecular mass cut-off $(3000 \mathrm{kDa}$, membrane length
$30 \mathrm{~mm}$, i.d. $0.50 \mathrm{~mm}$ ) were inserted under ultrasound guidance in the peritendinous spaces of patellar tendons as previously described (Langberg et al., 1999). The inflow tube of the microdialysis catheter was connected to a high-precision syringe pump with an infusion rate of $2 \mu \mathrm{L} / \mathrm{min}$. The catheters were perfused with a Ringer-acetate solution mixed with a small amount of radioactive labeled glucose $\left[\mathrm{D}-\left(3-{ }^{3} \mathrm{H}\right)\right.$-glucose in aqueous solution steri-pack, Perkin Elmer Life and Analytical Science, Boston, MA, USA, Net 331A, lot\#3559-801]. The total amount of radioactivity that the patients received was less than $0.001 \mathrm{mSv}$. A sample vial was placed at the end of the outflow tube, and after 30 min perfusion of the catheter, dialysate was collected in three 1-h periods and stored at $-80{ }^{\circ} \mathrm{C}$ until the analyses were performed. The relative recovery over the membrane was determined for each dialysate sample (Scheller \& Kolb, 1991). The dialysate $(3 \mu \mathrm{L})$ was pipetted into a counting vial in duplicates and mixed with $3 \mathrm{~mL}$ scintillation fluid (Ultima Gold, Perkin Elmer, Boston, MA, USA) and the samples were counted in a $\beta$-counter. The mean relative recoveries for the microdialysis catheters did not differ between the control and IGF-I leg (Control $34 \pm 3 \%$, IGF-I leg: $39 \pm 3 \%, P=0.25$ ).

Dialysate collected in the time period from 3.5 to $4.5 \mathrm{~h}$ after the last injections was used for analyses of PINP using a sandwich enzyme-linked immunosorbent assay utilizing a purified alpha 1-chain specific rabbit antibodies (donated by Teisner B, Department of Medical Microbiology, University of Southern Denmark, Odense, Denmark) (Jensen et al., 1998). The within- (double determination) and between-assay coefficients of variations (CVs) were (on average) $2.2 \%$ and $4.9 \%$, respectively.

\section{IGF-I concentrations}

All blood samples were taken from a cubital vein into sealed vials. After separation by centrifugation, serum was stored at $-80^{\circ} \mathrm{C}$ until analysis. A serum sample collected $1.5 \mathrm{~h}$ after the last injections was used for analysis of circulating IGF-I. Tendon dialysate collected 2.5 to $3.5 \mathrm{~h}$ after the injections was used for analyses of IGF-I. Serum IGF-I and tendon dialysate IGF-I were determined by time-resolved immunofluorimetic assay after acid-ethanol extraction, as previously described (Frystyk et al., 1995). All samples were measured in the same assay run (intra-assay CV\% $<5 \%)$.

\section{Statistical analysis}

Data are presented as median and range for interstitial IGF-I, whereas all other data are presented as mean \pm standard error of the mean. Nonparametric statistics (Wilcoxon signed-rank test) was used to test for difference in interstitial IGF-I between IGF-I leg and control leg because data were not normally distributed. Student paired $t$-test was used to test for differences between the legs for the remaining parameters. The level of significance was set at $P<0.05$.

\section{Results}

The interstitial tissue concentration of IGF-I determined locally in the peritendinous tissue in front of the patellar tendon 1-2 $\mathrm{h}$ after the last injections was higher in the IGF-I leg compared with the control leg in all subjects [median 7.95 (range $0.20-50.34$ ) $\mathrm{mg} / \mathrm{L}$ vs 0.01 (range $0.00-0.05) \mathrm{mg} / \mathrm{L}, P<0.05$ ] and also much higher when compared with the circulating IGF-I $(0.31 \pm 0.02 \mathrm{mg} / \mathrm{L}$, $P<0.05)$. 


\section{Hansen et al.}

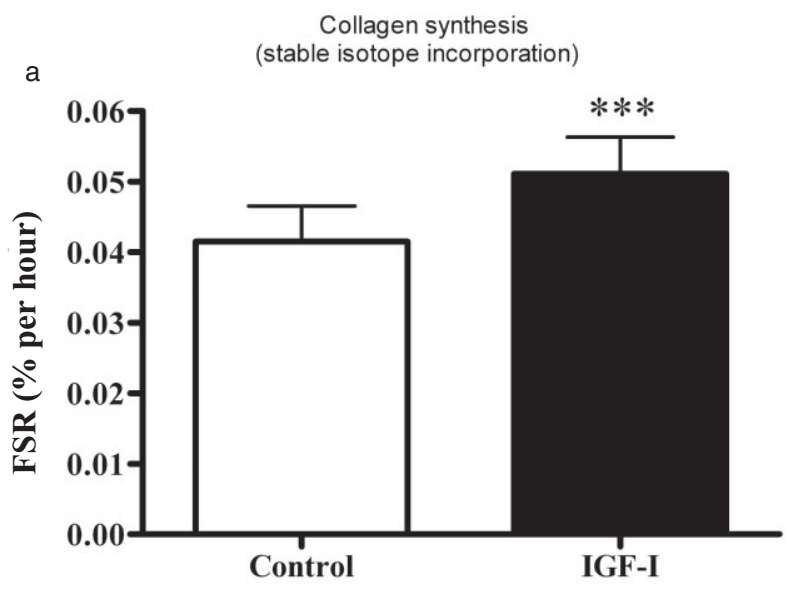

b

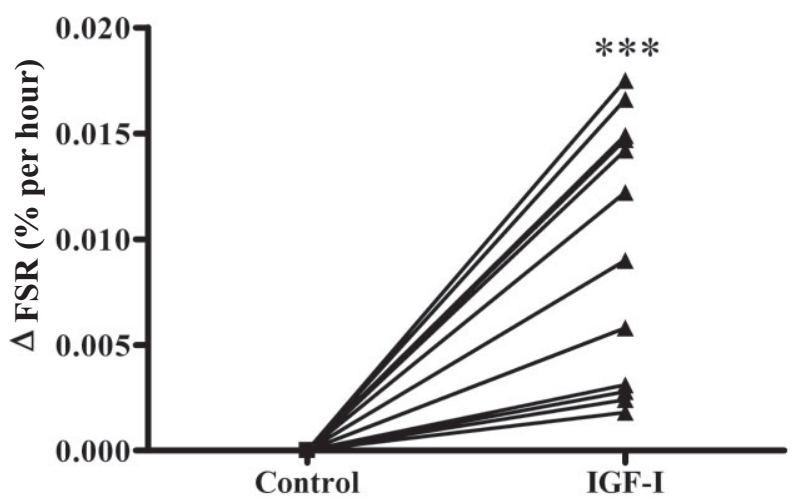

Fig. 2. Tendon fractional synthesis rate. (a) Tendon collagen fractional synthesis rate (FSR) in the patellar tendon in the control leg exposed to saline injections (control) and the leg exposed to insulin-like growth factor I (IGF-I) injections $(n=12$ paired-samples). Stable isotope incorporation $\left({ }^{13} \mathrm{C}\right.$-proline) into tendon collagen was determined from tendon biopsies. Values are mean \pm standard error of the mean (SEM). (b) Individual responses in tendon fractional synthesis rate (FSR) after IGF-I injections compared with the control. $* * * P<0.001$.

Tendon collagen FSR was significantly higher in the IGF-I leg compared with the control leg $(0.051 \pm 0.005$ vs $0.041 \pm 0.005 \% / \mathrm{h}, P<0.001)$ in the period from 1.5 to $4.5 \mathrm{~h}$ after the last injections (Fig. 2(a)). The increase in tendon FSR was evident in all 12 subjects; however, the size of the increase was different (Fig. 2(b)).

Similar to tendon collagen FSR, the indirect marker for type I collagen synthesis, (PINP) in the peritendinous tissue, was significantly enhanced 2 to $3 \mathrm{~h}$ after the last injections in the IGF-I leg compared with the control leg $(103 \pm 21$ vs $60 \pm 12 \mu \mathrm{g} / \mathrm{L}, P<0.05)$ (Fig. 3$)$. Analyses for PINP and IGF-I in the dialysate were performed on samples from 11 subjects (paired samples), because of catheter diffusion problems in one of the microdialysis catheters in one subject.
Collagen synthes is (peritendinous microdialysis)

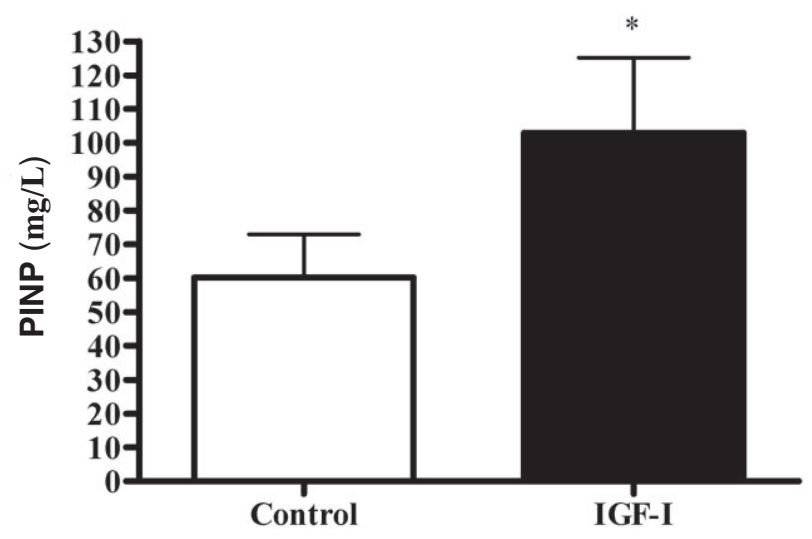

Fig. 3. Type I collagen synthesis (PINP). N-terminal propeptide of human procollagen type I (PINP) in peritendinous tissue in front of the patellar tendon measured with the microdialysis technique in the control leg exposed to saline injections (control) and the leg exposed to insulin-like growth factor I (IGF-I) injections ( $n=11$ paired-samples). Values are mean \pm standard error of the mean (SEM). $* P<0.05$.

\section{Discussion}

The novel finding in the present study was a significant increase in tendon collagen synthesis rate after local injections of IGF-I into the patellar human tendon compared with the injection of saline in the contralateral tendon of the same individual. The size of the enhancement of the synthesis rate was variable between subjects. This could be due to difficulties in obtaining the tendon biopsy exactly in the injection site. Nevertheless, a significantly higher tendon collagen synthesis rate after IGF-I injections measured by both methodological approaches in this study. On one side, the use of the stable isotopes to determine changes in the tendon tissue as well as by using the microdialysis technique to evaluate collagen synthesis peritendinously (Langberg et al., 1999), it was confirmed that IGF-I administration has a direct stimulating effect on collagen synthesis in human connective tissue.

IGF-I is not only synthesized and secreted to the circulation from the liver, but is also expressed and synthesized locally in tendons and ligaments (Tsuzaki et al., 2000; Olesen et al., 2006a). In healthy human subjects, an enhanced IGF-I mRNA expression has been observed in tendon tissue after systemic GH administration simultaneously with an increase in tendon collagen expression and synthesis (Doessing et al., 2010a). Furthermore, in patients with acromegaly and GH deficiency, positive correlations between local IGF-IEa mRNA expression and muscle collagen I and III mRNA expression have been observed (Doessing et al., 2010b). These earlier findings, together with the present results, support a regulatory role of local IGF-I on collagen synthesis. Fur- 
Effect of IGF-I on tendon collagen synthesis

thermore, a stimulating effect of local IGF-I administration on collagen synthesis is in agreement with the previous results from in vitro and animal studies. Administration of IGF-I to canine anterior cruciate ligament fibroblast has been shown to enhance collagen production and type I to III collagen ratio (DesRosiers et al., 1996), whereas administration of anti-IGF-I antibody eliminated most of the mitogenic activity in avian tendon tissue (Tsuzaki et al., 2000).

In physiological situations, like in response to mechanical loading, an association between an enhanced synthesis and release of IGF-I and a simultaneous increase in tendon collagen expression has been observed in animals (Heinemeier et al., 2007; Olesen et al., 2006b). In human subjects, only a few studies have measured IGF-I in the interstitial fluid in peritendinous tissue at rest and in response to acute exercise. In the present study, the concentration of peritendinous IGF-I in the control leg corresponded to what has previously been reported peritendinous during rest (Hansen et al., 2008). No significant change in peritendinous IGF-I was detected in previous studies in response to acute exercise, despite that tendon collagen synthesis was enhanced (Miller et al., 2005; Olesen et al., 2006a). However, no measurement of tissue concentration of IGF-I within the tendon tissue was performed in these studies. Thus, it cannot be ruled out that mechanical loading enhance IGF-I mRNA expression and production within the tendon and thereby stimulate collagen synthesis within the tendons. The present data support such a role, and the increase in tendon collagen FSR in the present study corresponds to the increase, which has been observed $6 \mathrm{~h}$ after 1 -h one-legged kicking in young men (from 0.045 to $0.057 \% \mathrm{hr}^{-1}$ ), but is lower than the synthesis rate measured $24 \mathrm{~h}$ postexercise (Miller et al., 2005). Therefore, based on these comparable observations, it can be hypothesized that IGF-I might have a regulatory role on tendon collagen synthesis in response to mechanical loading, but IGF-I is just one of more growth factors, and probably not the major stimulating agent. Another possibility is that the stimulating effect of IGF-I is short-term and only influence the initial rise in tendon collagen synthesis after mechanical loading. That supports the view that it is predominantly the last injection of IGF-I in the present study, which led to an increase in tendon collagen synthesis.

In the present study, the injection of IGF-I was placed in the mid-substance of the patella tendon, and ultrasonography assisted the guiding of the needle to ensure placement of the substance. Evidently, it is difficult to document exactly how much the injected volume will spread, but from a recent cadaver study, it is likely that the injected substance will spread proximally and distally along the loose connective tissue between fascicles (Wiegerinck et al., 2011). Furthermore, it cannot be excluded that part of the injected IGF-I will disappear via the injection canal. This might have happened as interstitial peritendinous tissue concentration of IGF-I was several (5000-6000×) fold elevated in some of the subjects compared with expected values. It could be hypothesized that in subjects where a greater fraction of the injected dose of IGF-I had disappeared into the peritendinous tissue and circulation, the response in tendon synthesis would be lower compared with other subjects where a greater fraction of the injected dose of IGF-I remained within the tendon. Nevertheless, no correlation between peritendinous IGF-I and tendon collagen FSR was observed to support this notion $(n=11, r=-0.26$, $P=0.22$ ). Furthermore, the fact that the circulating level of IGF-I was maintained at a normal level indicates that the two injections of IGF-I into the tendon did not result in any marked disappearance of IGF-I from the tendon region.

\section{Perspectives}

It may be hypothesized that an additional external stimulation of the fibroblasts by growth factors such as IGF-I may optimize and accelerate tissue healing and shorten time to functional recovery. This is supported by in vitro (Abrahamsson et al., 1991a, b; Abrahamsson \& Lohmander, 1996; DesRosiers et al., 1996; Murphy \& Nixon, 1997) and animal studies (Kurtz et al., 1999; Dahlgren et al., 2002; Provenzano et al., 2007). Systemic administration of IGF-I after surgical disruption of rat knee medial collateral ligaments has been shown to improve matrix organization, type I collagen expression, type I to type III collagen ratio, and tissue strength with up to $\sim 60 \%$ compared with the healing process observed in rats receiving only saline (Provenzano et al., 2007). Similarly, after collagenase-induced degradation, reduced soft tissue swelling, smaller lesion size, and a trend toward improvement of tendon mechanical properties has been observed after 10 local IGF-I injections compared with saline (Dahlgren et al., 2002). To summarize, the present observation of enhanced tendon collagen synthesis after injections of a high local dose of rhIGF-I may indicate that local IGF-I plays an important physiological role in the regulation of collagen-rich tissues. Furthermore, the observation could have implications for connective tissue injury and rehabilitation.

Key words: extracellular matrix protein, connective tissue, protein metabolism.

\footnotetext{
Abbreviations

BMI body mass index; $\mathrm{CV}$ variation coefficient; $\Delta \mathrm{E}_{\mathrm{t}}$ change in enrichment of proline; $\mathrm{AUC}_{\mathrm{p}}$ is the area under the curve of venous proline labeling with the exact time in hours from the flood until the individual biopsies are obtained; $\mathrm{Hb}$ hemoglobin; IGF-I insulin-like growth factor-I; PINP amino terminal propeptide of type I collagen; $\mathrm{VO}_{2 \max }$, est, estimated maximal oxygen uptake per min per kg body weight.
} 


\section{Hansen et al.}

\section{Acknowledgements}

We thank the subjects for their time and devotion to the study. Additionally, we thank Ann-Marie Sedstrom, Ann Christina R. Reimann, Anja Jokipii, Camilla Hansen, Karen Mathiassen, and Kirsten Nyborg for their technical assistance.

This work was supported by the Danish Rheumatism Association, the Danish Medical Research Council, the Danish Health
Science Research Board, EU 7th framework grant "Myoage", Nordea Foundation (Healthy Ageing grant), the Lundbeck Foundation, Novo Nordisk Foundation, the HS Foundation, the Eva and Henry Frænkels Memorial Foundation, Clinical Institute at Aarhus University Hospital, The A.P. Møller Foundation for the Advancement of Medical Science, and Anti-doping Denmark.

Conflict of interest: No conflicts of interest to disclose.

\section{References}

Abrahamsson SO, Lohmander S. Differential effects of insulin-like growth factor-I on matrix and DNA synthesis in various regions and types of rabbit tendons. J Orthop Res 1996: 14: 370-376.

Abrahamsson SO, Lundborg G, Lohmander LS. Long-term explant culture of rabbit flexor tendon: effects of recombinant human insulin-like growth factor-I and serum on matrix metabolism. J Orthop Res 1991a: 9: 503-515.

Abrahamsson SO, Lundborg G, Lohmander LS. Recombinant human insulin-like growth factor-I stimulates in vitro matrix synthesis and cell proliferation in rabbit flexor tendon. J Orthop Res 1991b: 9: 495-502.

Babraj J, Cuthbertson DJ, Rickhuss P, Meier-Augenstein W, Smith K, Bohe J, Wolfe RR, Gibson JN, Adams C, Rennie MJ. Sequential extracts of human bone show differing collagen synthetic rates. Biochem Soc Trans 2002: 30: 61-65.

Babraj JA, Cuthbertson DJ, Smith K, Langberg H, Miller BF, Krogsgaard MR, Kjaer M, Rennie MJ. Collagen synthesis in human musculoskeletal tissues and skin. Am J Physiol Endocrinol Metab 2005: 289: E864-E869.

Dahlgren LA, van der Meulen MC, Bertram JE, Starrak GS, Nixon AJ. Insulin-like growth factor-I improves cellular and molecular aspects of healing in a collagenase-induced model of flexor tendinitis. J Orthop Res 2002: 20: 910-919.

DesRosiers EA, Yahia L, Rivard CH. Proliferative and matrix synthesis response of canine anterior cruciate ligament fibroblasts submitted to combined growth factors. J Orthop Res 1996: 14: 200-208.

Doessing S, Heinemeier KM, Holm L, Mackey AL, Schjerling P, Rennie M, Smith K, Reitelseder S, Kappelgaard AM, Rasmussen MH, Flyvbjerg A, Kjaer M. Growth hormone stimulates the collagen synthesis in human tendon and skeletal muscle without affecting myofibrillar protein synthesis. J Physiol 2010a: 588 (2): 341-351.
Doessing S, Holm L, Heinemeier KM, Feldt-Rasmussen U, Schjerling P, Qvortrup K, Larsen JO, Nielsen RH, Flyvbjerg A, Kjaer M. GH and IGF1 levels are positively associated with musculotendinous collagen expression: experiments in acromegalic and $\mathrm{GH}$ deficiency patients. Eur J Endocrinol 2010b: 163: 853-862.

Finni T, Komi PV, Lepola V. In vivo human triceps surae and quadriceps femoris muscle function in a squat jump and counter movement jump. Eur J Appl Physiol 2000: 83: 416-426.

Frystyk J, Dinesen B, Ørskov H. Non-competitive time-resolved immunofluorometric assays for determination of human insulin-like growth factor I and II. Growth Regul 1995: 5: 169-176.

Hansen M, Koskinen S, Petersen SG, Doessing S, Frystyk J, Fiyvbjerg A, Westh E, Magnusson SP, Kjaer M, Langberg H. Ethinyl estradiol administration in women suppresses synthesis of collagen in tendon in response to exercise. J Physiol 2008: 586 (12): 3005-3016.

Heinemeier KM, Olesen JL, Schjerling P, Haddad F, Langberg H, Baldwin KM, Kjaer M. Short-term strength training and the expression of myostatin and IGF-I isoforms in rat muscle and -tendon: differential effects of specific contraction types. J Appl Physiol 2007: 102 (2): 573-581.

Jensen CH, Hansen M, Brandt J, Rasmussen HB, Jensen PB, Teisner B. Quantification of the N-terminal propeptide of human procollagen type I (PINP): comparison of ELISA and RIA with respect to different molecular forms. Clin Chim Acta 1998: 269: 31-41.

Kjaer M. Role of extracellular matrix in adaptation of tendon and skeletal muscle to mechanical loading. Physiol Rev 2004: 84: 649-698.

Kurtz CA, Loebig TG, Anderson DD, DeMeo PJ, Campbell PG. Insulin-like growth factor I accelerates functional recovery from Achilles tendon injury in a rat model. Am J Sports Med 1999: 27: 363-369.

Langberg H, Skovgaard D, Petersen LJ, Bülow J, Kjaer M. Type I collagen synthesis and degradation in peritendinous tissue after exercise determined by microdialysis in humans. J Physiol 1999: 521: 299-306.

Meier-Augenstein W. Applied gas chromatography coupled to isotope ratio mass spectrometry. J Chromatogr A 1999: 842: 351-371.

Miller BF, Olesen JL, Hansen M, Dossing S, Crameri RM, Welling RJ, Langberg H, Flyvbjerg A, Kjaer M, Babraj JA, Smith K, Rennie MJ. Coordinated collagen and muscle protein synthesis in human patella tendon and quadriceps muscle after exercise. J Physiol 2005: 567: 1021-1033.

Murphy DJ, Nixon AJ. Biochemical and site-specific effects of insulin-like growth factor I on intrinsic tenocyte activity in equine flexor tendons. Am J Vet Res 1997: 58: 103-109.

Olesen JL, Heinemeier KM, Langberg H, Magnusson SP, Kjaer M, Flyvbjerg A. Expression, content, and localization of insulin-like growth factor I in human Achilles tendon. Connect Tissue Res 2006a: 47: 200-206.

Olesen JL, Langberg H, Heinemeier KM, Flyvbjerg A, Kjaer M. Determination of markers for collagen type I turnover in peritendinous human tissue by microdialysis: effect of catheter types and insertion trauma. Scand J Rheumatol 2006b: 35: 312-317.

Provenzano PP, Alejandro-Osorio AL, Grorud KW, Martinez DA, Vailas AC, Grindeland RE, Vanderby R Jr. Systemic administration of IGF-I enhances healing in collagenous extracellular matrices: evaluation of loaded and unloaded ligaments. BMC Physiol 2007: doi:10.1186/14726793-7-2.

Scheller D, Kolb J. The internal reference technique in microdialysis: a practical approach to monitoring dialysis efficiency and to calculating tissue concentration from dialysate samples. J Neurosci Methods 1991: 40: 31-38.

Schwenk WF, Berg PJ, Beaufrere B, Miles JM, Haymond MW. Use of t-butyldimethylsilylation in the gas chromatographic/mass spectrometric analysis of physiologic compounds 
Effect of IGF-I on tendon collagen synthesis

found in plasma using electron-impact ionization. Anal Biochem 1984: 141: 101-109.

Tsuzaki M, Brigman BE, Yamamoto J, Lawrence WT, Simmons JG,

Mohapatra NK, Lund PK, Van Wyk J,
Hannafin JA, Bhargava MM, Banes AJ. Insulin-like growth factor-I is expressed by avian flexor tendon cells. J Orthop Res 2000: 18: 546-556.

Wiegerinck JI, Reilingh ML, de Jonge MC, van Dijk CN, Kerkhoffs GM.
Injection techniques of platelet-rich plasma into and around the Achilles tendon: a cadaveric study. Am J Sports Med 2011: 39 (8): 1681-1686. 